\title{
COMMUNICATIONS
}

\section{OCULAR ABNORMALITIES OF THE FOETUS WITH SPECIAL REFERENCE TO CYCLOPIA*†}

\author{
BY \\ VISHNU SARMA \\ From the Government Women and Children's Hospital, Egmore, Madras, South India
}

THIS curious malformation in which the eyes are fused together (synophthalmia), which derives its name from Cyclops, the one-eyed giant of Greek legend, is a common foetal ocular anomaly. Such a serious degree of maldevelopment is incompatible with survival and is therefore usually encountered by obstetricians rather than ophthalmic surgeons.

Géoffroy Saint Hilaire (1832) attempted to differentiate five types of cyclopia in man. According to Ballantyne $(1902,1904)$ it is particularly common in the lower mammals and is as frequent in some species as anencephaly in man.

Embryology.-The optic vesicle lies between the paraxial mesoderm of the head fold and the maxillary process derived from the first visceral arch in the early stages of development. The orbit is formed at the $12-16 \mathrm{~mm}$. stage (i.e. at 6 weeks). After a primary failure of development of the anterior neural tube, the fronto-nasal processes fail to develop and there is probably compensatory overgrowth of the first visceral arch. Fusion of the orbits with their contents results in cyclopia (Mann, 1957, p. 55). On the other hand underdevelopment of structures arising from the first visceral arch leads to mandibulo-facial dysostosis.

The cyclopia may take different forms:

(1) The two orbits may be distinctly but closely set. A median rudimentary nose with a single nostril may be present in between (cebocephaly) or the nose may be represented by a tubular structure of skin and soft tissues continuous with the forehead.

(2) The two orbits may be fused into a single diamond-shaped cavity, containing two eyes showing varying degrees of fusion. This is the commonest abnormality and most monsters described in the literature fall into this group. The two eyes may be contiguous. There may be a single eyeball which is considerably widened and contains a double lens or double cornea placed side by side.

* Received for publication May 10, 1962.

+ Based on a dissertation for the M.D. Degree, Cambridge University, 1958. 
There may be a single rudimentary eye, and in some cases the eyeball is shrivelled (Fig. 1). The nose is absent or is represented by a snout-like proboscis (Fig. 2), which may contain a cavity lined by ciliary epithelium. The cavity has an external aperture, and internally is intimately related to the ethmoid and lamina cribrosa regions.

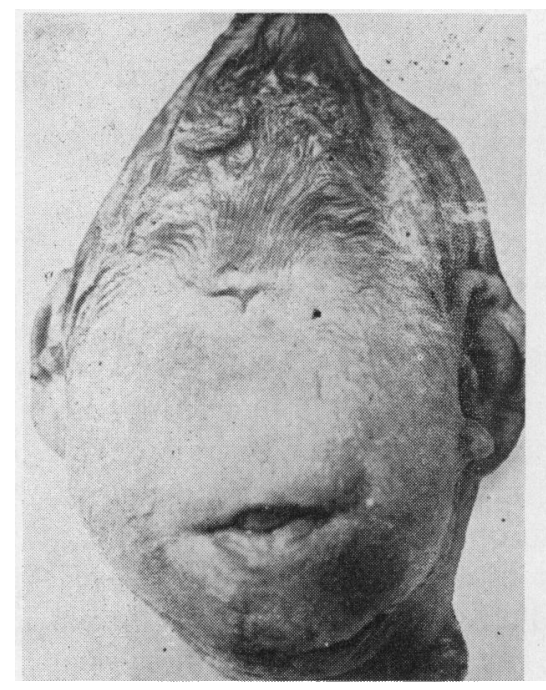

Fig. 1.-Cyclops malformation.

Fig. 2.- Female cyclops with exomphalos and polydactyly, six digits on each hand. A proboscis is present.

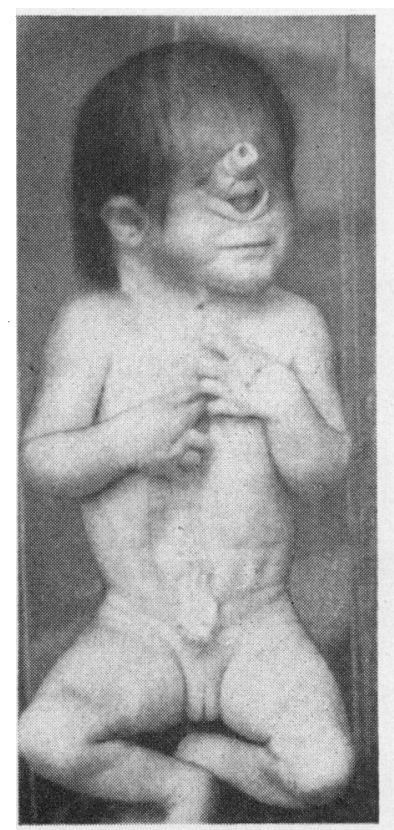

Anatomy.-The skull is ordinarily somewhat small. The middle fossae occupy a disproportionately large area of the base of the skull. The posterior and anterior fossae are greatly reduced in size. The small anterior fossae are undivided and contain a single opening to transmit the optic nerve. The foramen is formed by the anterior part of the body of the sphenoid. The sella turcica and clinoid process are absent. The floor of the orbit is made up anteriorly by the malar bones (which are not united to the frontal bones) and posteriorly by the superior maxilla and palatine bones (parts of which are developed in the maxillary process). Incisor teeth are absent because the intermaxillary process is not developed and their place is taken in the middle by canines. The frontal bones meet in the midline to form the roof of the orbit. Often, several bones such as the ethmoid, pre-sphenoid, inferior turbinates, nasal, lacrimal, and premaxillae are missing.

The bony portion of the nose is absent. The superior maxilla and vomers are approximated. The palate is closed and usually abnormally high. The lip has no philtrum.

The optic nerve itself is usually single, and may be underdeveloped or even absent. The third and sixth nerves are absent or hypoplastic. 
The malformation of the brain appears to be as catastrophic as that of the eye. The cerebral hemispheres are fused into a single mass and the brain substance is reduced to one-third or less of its normal volume. A single open ventricle is present. The olfactory nerves, corpus callosum, and septum pellucidum are absent. The convolutions are poorly developed, and there are few blood vessels on the brain surface (Potter, 1952).

Associated Abnormalities and Obstetric Complications.-Other external abnormalities are not commonly present, but polydactyly (Fig. 2), exomphalos (Fig. 3), and even anencephaly (Figs 4 and 5) and hydrocephaly (Fig. 6, overleaf) may be associated with cyclopia.

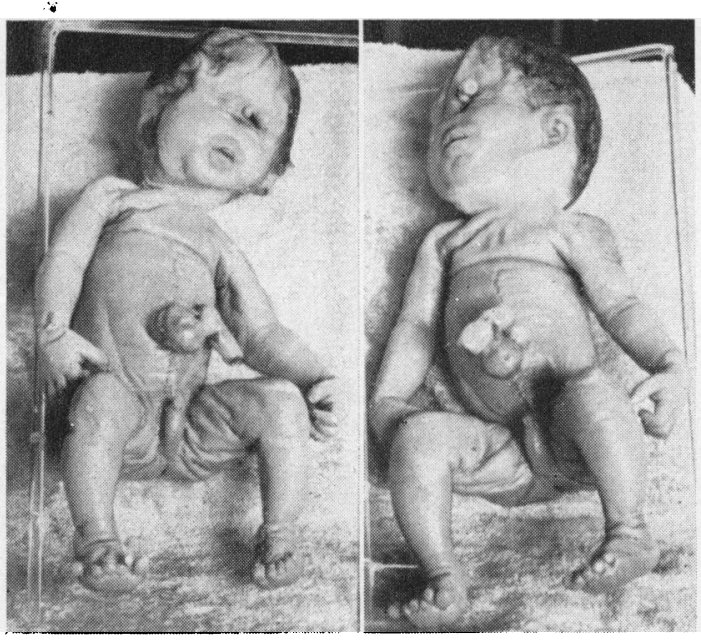

Fig. 3.-Male cyclops with ventral hernia and polydactyly, six digits on each hand and on the right foot.

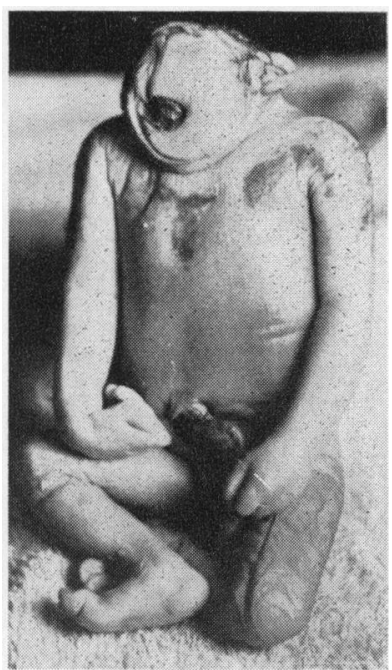

Fig. 4.-Female cyclops with anencephaly, and bifid thumb on the right hand.
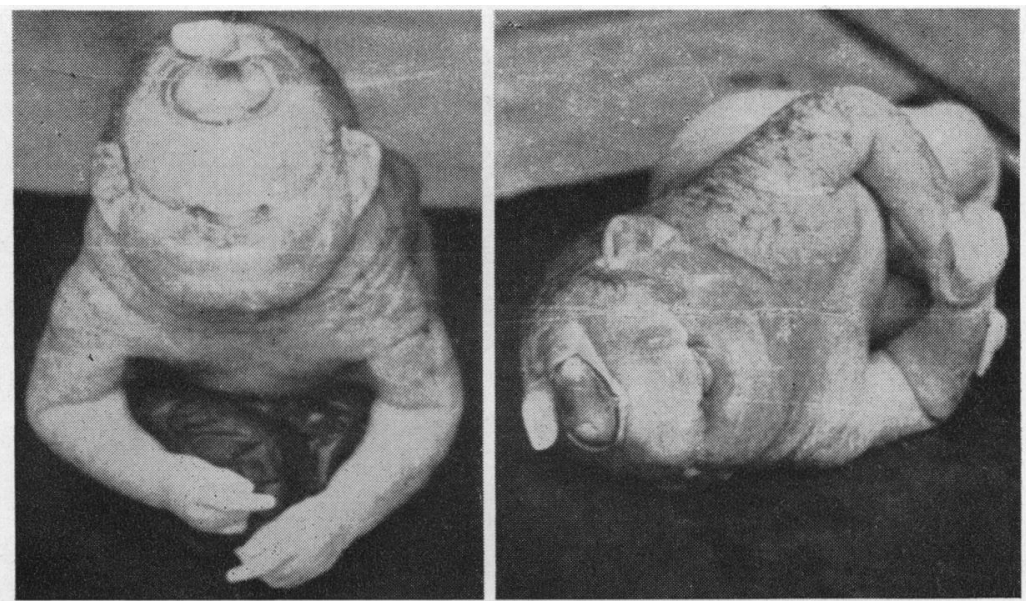

FIG. 5.-Cyclops with anencephaly. A proboscis is present. 


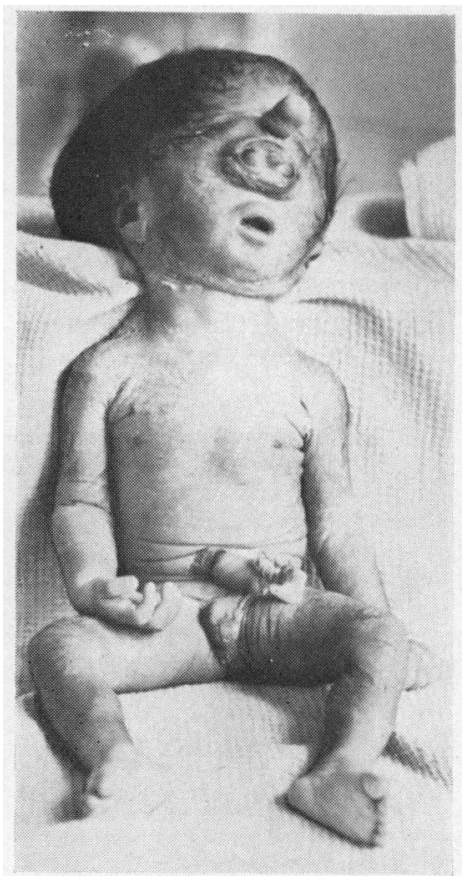

FIG. 6.-Cyclops with hydrocephaly. A proboscis is present.

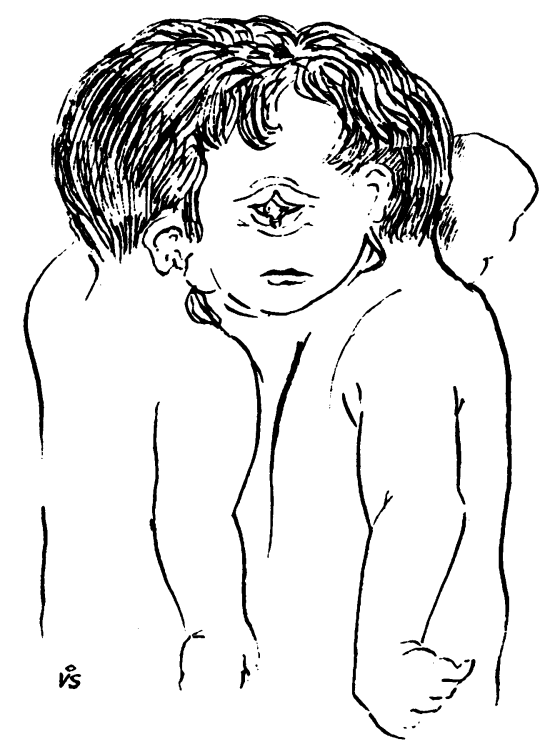

Fig. 7.-Cephalo-thoracopagus with cyclopia (Sarma, 1955).

Serbin (1933) reported a case of hydrocephalus and cebocephalus. There was labour dystocia, and craniotomy and cleidotomy were required before delivery could be effected. There was also cyclopia, cleft upper-lip (not hare-lip), bilateral cleft-palate, bilateral pes varus, and absence of the external ears and the nose. The hydrocephalus was the cause of the dystocia, the cyclopia being an incidental malformation.

Craig (1886) recorded the birth by breech presentation of a male cyclops to a VII-para, whose labour was complicated by polyhydramnios, and Bachman (1927) saw the same complication at the birth of a female cyclops to a 21year-old woman (parity not stated).

Coffey and Clarke (1960) recorded the birth to a 42-year-old VII-para of a female cyclops which lived for 2 days. Polyhydramnios was not mentioned.

Cyclopia is occasionally encountered in double or double-headed monsters (Fig. 7, above, and Fig. 13, p. 201).

Bramwell (1880) recorded the case of a VI-para who gave birth to twins, one of which was a cyclops, and I have a similar example in my own series (see Case 4, p. 199). 


\section{Personal Observations of Congenital Ocular Anomalies}

My earlier series of 543 congenitally abnormal infants (Sarma, 1958) included eight examples of ocular malformation. Six showed cyclopia, one had been registered as showing "congenital protrusion of the right eye-ball" (? exophthalmos or retinoblastoma), and one showed microphthalmos. I have also observed a case in which foetal microcephaly and anophthalmos were associated with maternal keratomalacia and vitamin A deficiency (Sarma, 1959). In another case, foetal microcephaly, microphthalmos, and enophthalmos were found in a child delivered by Caesarean section to a multipara with placenta praevia (see Fig. 12, p. 200).

Cyclopia.-One remarkable feature is the high parity of most of the mothers. Two of my six cases were XI-paras, two X-paras, one a V-para, and only one a primigravida. Five mothers had polyhydramnios. This type of malformation does not in itself give rise to labour dystocia; most of the foetuses are small and are delivered prematurely and spontaneously. The average birth weight of my six cases was $3 \mathrm{lb} .4 \mathrm{oz}$. The sex ratio is also remarkable; there were five females to one male.

In one instance (Case 4) the female cyclops was the first of a pair of twins, the other twin being a male and apparently normal.

I have since added a seventh example which conforms to this general pattern (Case 5). A female cyclops weighing $2 \frac{1}{2} \mathrm{lb}$. was born prematurely to a woman with pre-eclamptic toxaemia and polyhydramnios. The unusual feature was the age (18 yrs) of the mother and the fact that this was the first child, an earlier pregnancy having ended in abortion.

\section{Case Reports}

Case 1, a 20-year-old primigravida, was admitted to hospital in labour, the membranes having ruptured one hour before admission. It was not known whether excessive liquor had been discharged. Her general health seemed to be satisfactory. The uterus was about 30 weeks in size and was acting normally. The foetus was lying longitudinally with vertex presentation. The foetal heart could not be heard, and the head was fixed. The patient soon gave birth to a stillborn female cyclops (Fig. 8a, overleaf). Other facial abnormalities resulted from disturbed branchial arch development; the mouth and mandible were missing, the ears almost met in the midline, and there was no proboscis. No other external abnormalities were seen. The third stage of labour was normal and the patient made an uneventful recovery. The foetus was $x$-rayed and the antero-posterior view showed, though not very clearly, the characteristic fused single orbit (Fig. $8 b$, overleaf).

Comment.-This case has already been described (Sarma, 1955). It is rare for a primigravida to give birth to a cyclops and the monster itself belongs to the rare class described by Potter (1952) as "cyclops hypognathus".

Case 2, a 38-year-old X-para, was admitted to hospital in labour with a history of 10 months' amenorrhoea. Her nine children had all been born at full term; five were still 

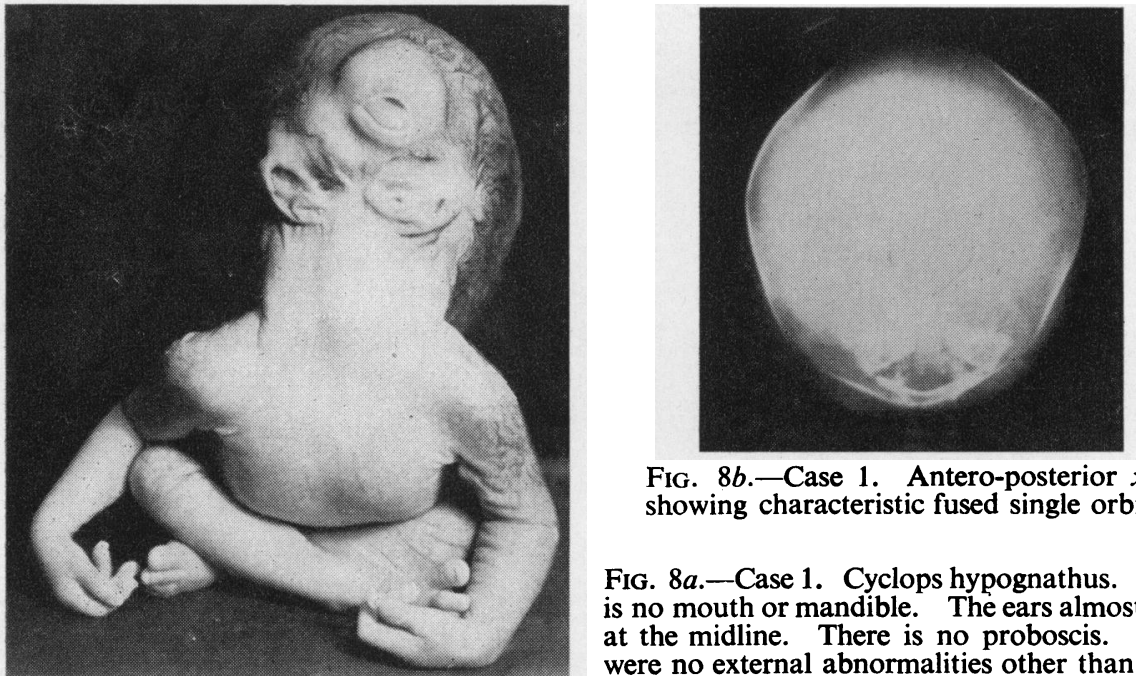

Fig. 8b.-Case 1. Antero-posterior $x$ ray, showing characteristic fused single orbit.

FIG. 8a.-Case 1. Cyclops hypognathus. There is no mouth or mandible. The ears almost meet at the midline. There is no proboscis. There were no external abnormalities other than those of the face (Sarma, 1955).

alive, and all were normal. During the present pregnancy she had experienced abdominal discomfort since the fifth month, with excessive abdominal distension. There had been no excessive foetal movements, antepartum vaginal bleeding, or evidence of toxaemia.

The body temperature was $101 \cdot 4^{\circ} \mathrm{F}$. The uterus was 32 weeks in size and was acting mildly, and the foetal parts were readily made out in spite of polyhydramnios. The foetus was lying longitudinally with vertex presentation. The head was mobile on palpation, and the foetal heart was palpable in the right lower quadrant of the abdomen. The membranes ruptured spontaneously and a large quantity of liquor was soon followed by the birth of a live female cyclops weighing $2 \frac{1}{2} \mathrm{lb}$. (Fig. $9 a, b$ ). Above the single central united eye was a characteristic proboscis, and there were six digits on the right hand. The child died after a few hours, and an $x$-ray was taken after death. The orbital cavity was almost obliterated on both sides but the union could be seen (Fig. 9c).

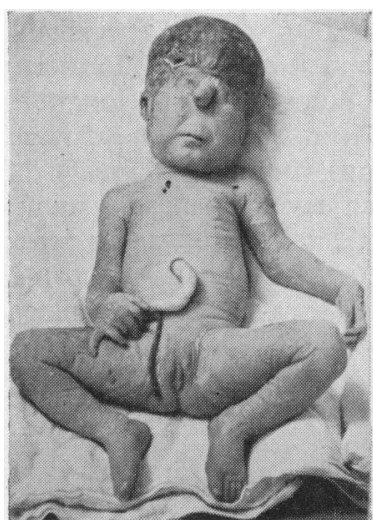

(a)

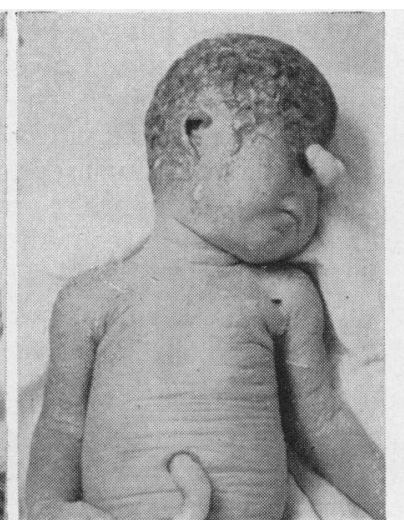

(b)

Fig. $9(a, b)$.-Case 2. Typical cyclops with proboscis and polydactyly, six digits on the right hand. 
Case 3, a 32-year-old V-para who had had four normal deliveries at term, came to the hospital in labour at the 32nd week. She was slightly anaemic with mild oedema of the feet. The uterus seemed to be slightly larger than normal but there was no clinical evidence of gross polyhydramnios. The foetal heart was audible and there was thought to be a small foetus presenting by the vertex. Within 4 hours the membranes ruptured spontaneously and a moderately large quantity of liquor was soon followed by a breech presentation; a female cyclops weighing $3 \frac{3}{4} \mathrm{lb}$. was delivered, and died within a few minutes (Fig. 10).

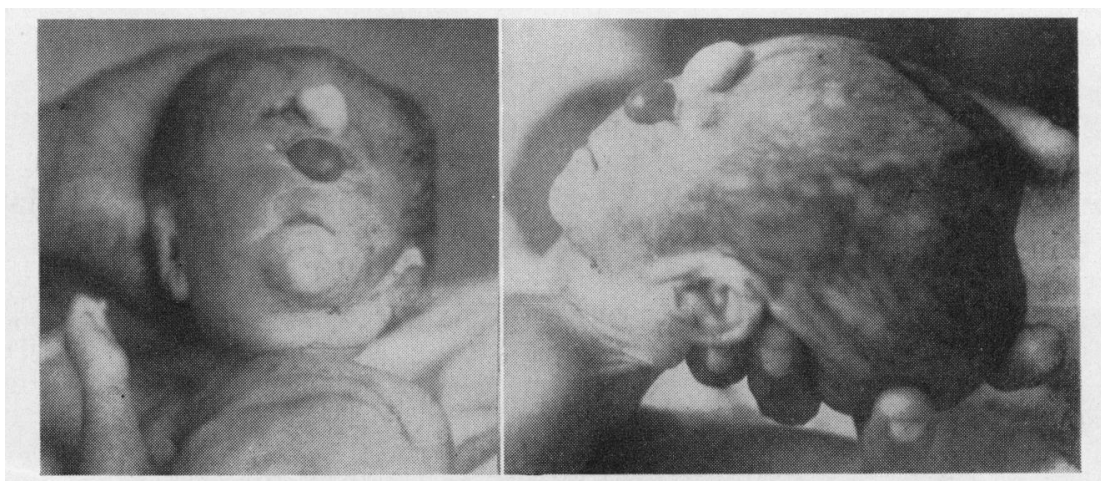

FIG. 10.-Case 3. Cyclops with proboscis and hydrocephalus.

Case 4, a 28-year-old XI-para, had had a twin pregnancy diagnosed and labour proceeded normally. The first child, which presented by the vertex and was born alive, was a female cyclops weighing $4 \mathrm{lb}$. The second, a male weighing $5 \mathrm{lb}$., presented by the breech and appeared to be normal. The placenta was retained and had to be removed under anaesthesia.

Case 5, an 18-year-old primipara, was admitted to hospital in labour at the 32nd week. The pregnancy had been complicated by mild pre-eclamptic toxaemia and polyhydramnios. The uterus was disproportionately large and there was a fluid thrill. The foetal heart was inaudible. A tense bag of membranes was presenting through a partially open cervix. The membranes soon ruptured spontaneously and a large quantity of liquor was followed by a female cyclops, weighing $2 \frac{1}{2} \mathrm{lb}$. A central fused eye could just be seen through a small median slit (Fig. 11). The patient had a satisfactory convalescence but the infant died within a few hours.

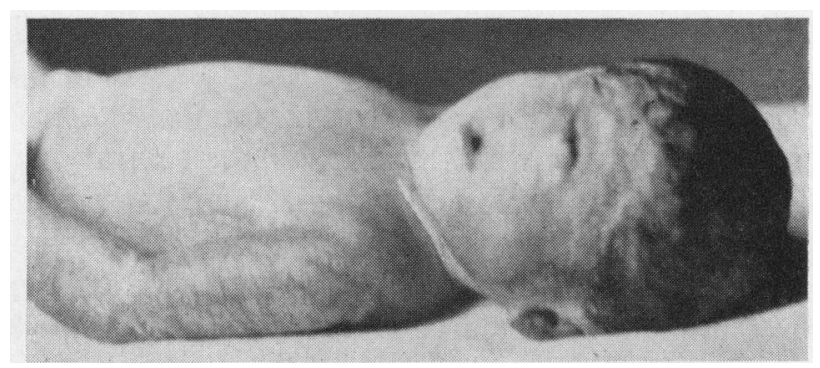

Fig. 11.-Case 5. Cyclops with small central eye but no proboscis.

Comment.-This case (not one of the six in my original series) is unusual in that this was the patient's second pregnancy, the first having ended in an abortion. 


\section{Diagnosis}

It should be possible by means of precision radiographs to diagnose cyclopia in utero. Instead of two orbital fossae, two contiguous hemi-fossae or a single united fossa may be seen (Hartley, 1949), but the observer may be misled by such factors as microcephaly and orbital tumours (White and Foster, 1955).

I have observed one unusual case of microcephaly with bilateral enophthalmos and microphthalmos (Fig. 12). The mother, a 27-year-old multipara, had antepartum haemorrhage at the 36th week and, placenta praevia being confirmed by soft tissue radiography, a female infant was delivered by Caesarean section. The ocular malformation could not be detected on the $x$ ray. According to Greenhill $(1923,1939)$ placenta praevia is associated with a high incidence of foetal abnormalities.

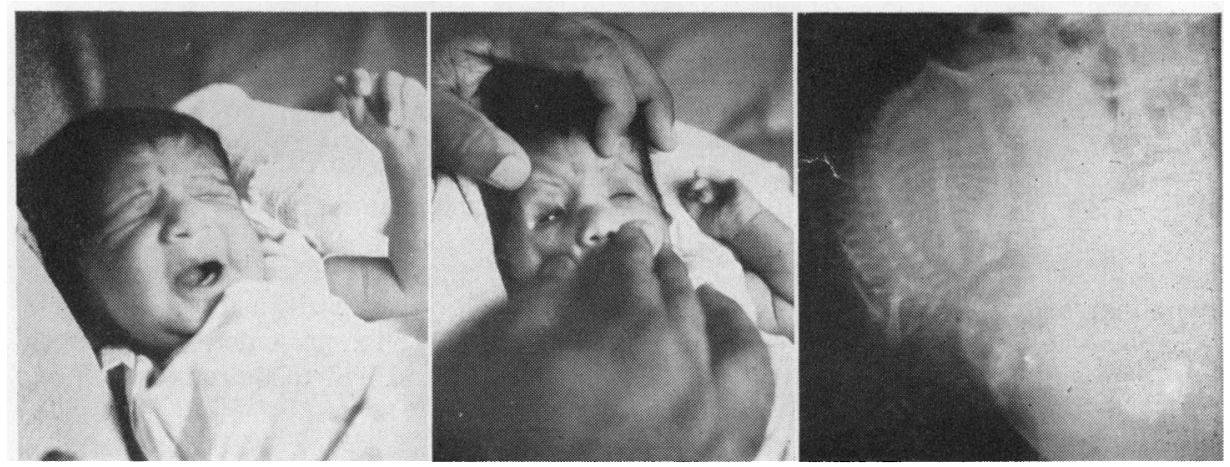

Fig. 12.-Female with microcephaly, bilateral enophthalmos, and microphthalmos. This ocular abnormality could not have been suspected from the pre-natal $x$ ray.

I have found no report in the literature of the pre-natal $x$-ray diagnosis of cyclopia in a single foetus, although theoretically this should be possible (Sarma, 1962). In my Case 1 (above: see Fig. $8 b$, p. 198) the single orbit was clearly seen in a post-natal radiograph and would probably have been visible ante partum as the membranes had ruptured prematurely and most of the amniotic fluid had drained away. In my Case 2 (above: see Fig. 9c, p. 198) a post mortem $x$ ray showed the single orbit, but this would probably have been obscured prenatally by the maternal hydramnios.

A unique case of diprosopus with three orbits, the central one being fused into a large single orbit, was diagnosed pre-natally by Latteier and Anderson (1952). The mother was a 19-year-old primipara whose pregnancy was complicated by pre-eclamptic toxaemia. A radiological examination at the 8th month showed an abnormally large uterus indicative of polyhydramnios; 4 days later an antero-posterior $x$ ray showed the diameter of the skull to be $11.6 \mathrm{~cm}$. and a tentative diagnosis of hydrocephalus was made; 2 weeks later a lateral $x$ ray suggested the presence of two mandibles and possibly three orbits. 
Labour was induced by artificial rupture of the membranes and a diprosopus was delivered with low forceps. It weighed $7 \mathrm{lb} .14 \mathrm{oz}$. at birth, and had a large head with two faces fused along their proximal lateral surfaces (Fig. 13a). There were four eyes (the middle two occupying a single large orbit, Fig. 13b,c), two noses, and two mouths. The creature lived for 16 days.

(a)
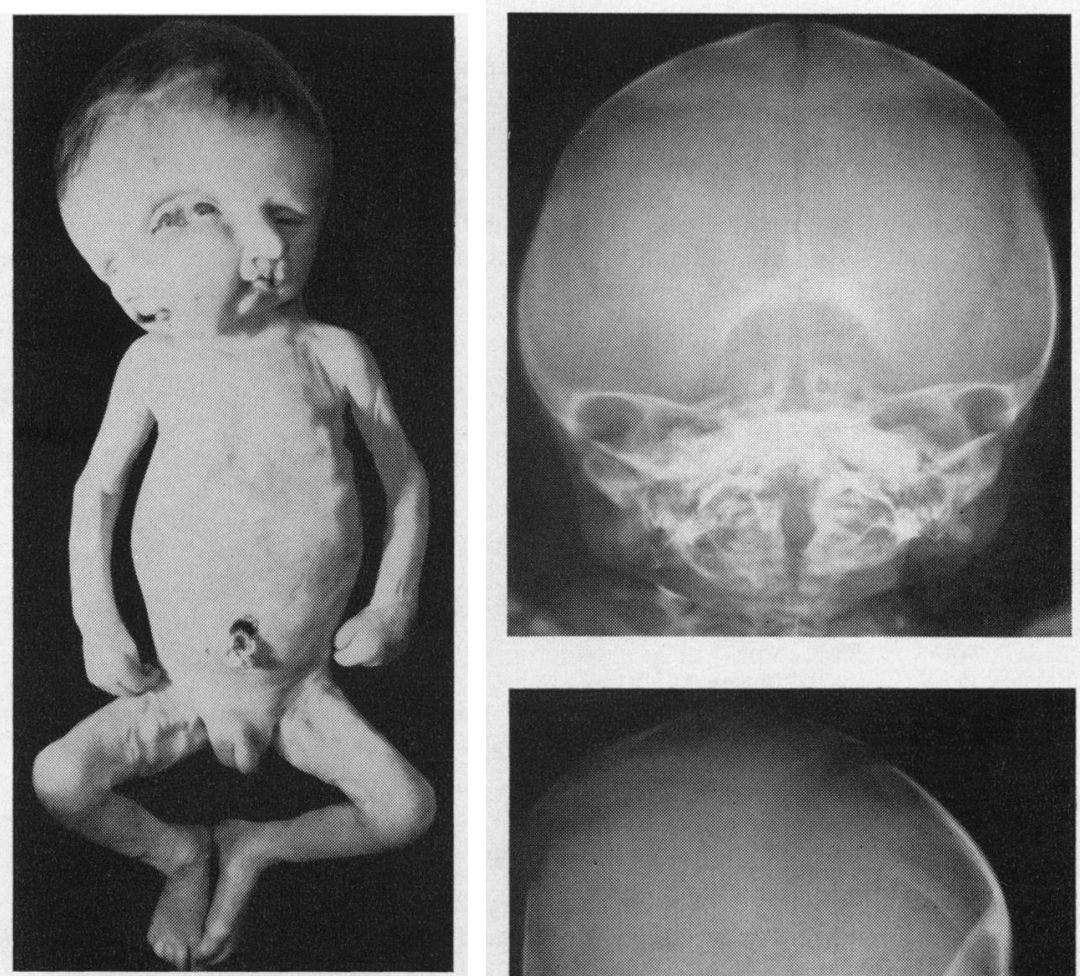

(b)

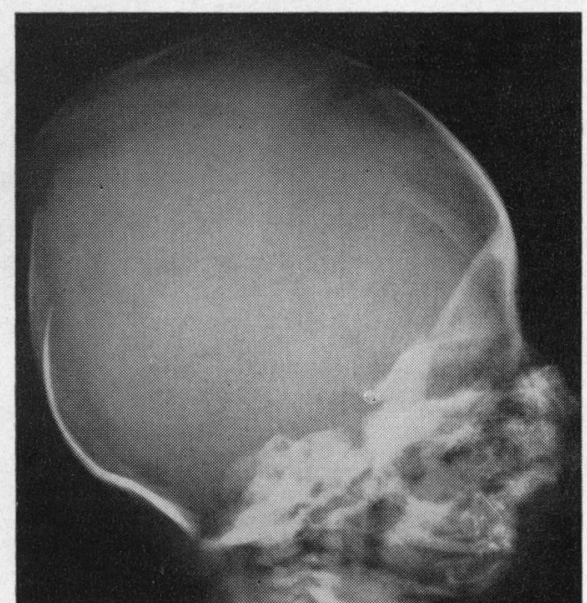

Fig. $13(a, b, c)$.-Diprosopus with three orbits. Hydrocephalus was suspected at first and subsequent $x$-ray studies enabled the condition to be diagnosed pre-natally with great precision. The identification of a fused central orbit should permit the pre-natal diagnosis of cyclops (Latteier and Anderson, 1952).

It seems desirable to make every effort to reach a diagnosis as early as possible, since the recognition of cyclopia would enable the fruitless pregnancy to be terminated by appropriate obstetric methods. 


\section{Summary}

The embryology and anatomy of cyclopia are briefly described and cases of associated congenital anomalies are reviewed. This malformation is too severe to permit survival even if the foetus is delivered alive.

A series of cases personally observed is described with reference to maternal age, parity, and obstetric history. If cyclopia can be diagnosed by intra-uterine radiological examination, a fruitless pregnancy may properly be terminated.

I wish to acknowledge my gratitude to Dr. Mrs. S. Abraham, M.D., Professor of Obstetrics and Gynaecology, Madras University, and Superintendent of the Government Women and Children's Hospital, Egmore, Madras, for permission to use clinical material from the hospital. I am specially indebted to Sir Stewart Duke-Elder for having reviewed this material and made valuable suggestions.

Figs 7 and $8 a$ are reproduced by courtesy of the Editor of the Journal of the Indian Medical Profession, and Figs 13a-c by courtesy of Drs. Latteier and Anderson and the Editor of Medical Radiography and Photography, Eastman Kodak Co., Rochester, New York.

\section{REFERENCES}

Bachman, C. (1927). Amer. J. Obstet. Gynec., 14, 797.

BallantYNe, J. W. (1902). "Manual of Ante-natal Pathology and Hygiene"-_The Foetus". William Green, Edinburgh. (1904). Ibid., "The Embryo".

Bock, K. E. (1889).' Klin. Mbl. Augenheilk., 27, 508 (Quoted by von Hippel, 1908).

BRAMWELl, B. (1880). Edinb. med. J., 26, 550.

Coffey, V. P., and Clarke, N. (1960). J. Irish med. Ass., 46, 139.

Craig, W. (1886). Edinb. med. J., 32, 193.

DARESTE, C. (1891). "Récherches sur la production artificielle des monstruosités". Reinwald, Paris. (Quoted by Bachman, 1927).

GÉOffroy SAINT HILAIRE, I. (1832-37). "Histoire générale et particulière des anomalies de l'organization chez l'homme et les animaux" ou "Traité de tératologie"; Vol. 1, 1832; Vols 2 and 3, 1836; Atlas, 1837. Baillière, Paris.

GreENHILL, J. P. (1923). Surg. Gynec. Obstet., 36, 227. (1939). Amer. J. Obstet. Gynec., 37, 624.

HANnover, A. (1882). "Anencephalia, Cyclopia, Synotia". Copenhagen. (Quoted by Bachman, 1927).

Hartley, J. B. (1949). Proc. roy. Soc. Med., 42, 301.

HIPPEL, E. VON (1908). In "Graefe-Saemisch Handbuch der gesamten Augenheilkunde", 2nd ed., band 2, abt. 1, kap. 9, p. 93 . Engelmann, Leipzig. (Quoted by Bachman, 1927).

Latteier, K. K., and Anderson, R. T. (1952). Med. Radiogr. Photogr., 28, 22.

PotTer, E. (1952). "Pathology of the Fetus and the Newborn". Yearbook Publishers, Chicago.

Sarma, V. (1955). J. Indian med. Prof., 2, 933. (1958). Dissertation for the M.D. Degree, Cambridge University.

(1959). Obstet. and Gynec., 13, 299.

(1962). "The Pre-natal Diagnosis of Foetal Abnormalities". Year Book of Indian Medical Sciences. Current Technical Literature, Co. Pvt. Ltd., Bombay.

Serbin, W. B. (1933). Amer. J. Obstet. Gynec., 25, 758.

White, G. M., and Foster, T. A. (1955). Canad. med. Ass. J., 72, 213. 